\title{
Blocking of efflux transporters in rats improves translational validation of brain radioligands
}

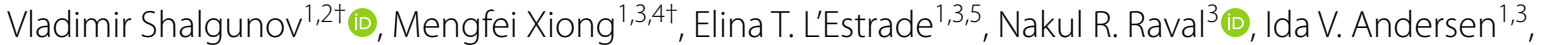 \\ Fraser G. Edgar ${ }^{1}$, Nikolaj R. Speth³, Simone L. Baerentzen ${ }^{3}$, Hanne D. Hansen ${ }^{3,6} \mathbb{C D}_{\text {, Lene L. Donovan }}^{3}$, \\ Arafat Nasser ${ }^{3}$, Siv T. Peitersen ${ }^{3}$, Andreas Kjaer ${ }^{2,7}$, Gitte M. Knudsen ${ }^{3,9}$, Stina Syvänen ${ }^{4}$, Mikael Palner 3,8 \\ and Matthias M. Herth ${ }^{1,2^{*}}$ (i)
}

\begin{abstract}
Background: Positron emission tomography (PET) is a molecular imaging technique that can be used to investigate the in vivo pharmacology of drugs. Initial preclinical evaluation of PET tracers is often conducted in rodents due to the accessibility of disease models as well as economic considerations. Compared to larger species, rodents display a higher expression and/or activity of efflux transporters such as the P-glycoprotein (P-gp). Low brain uptake could, therefore, be species-specific and uptake in rodents not be predictive for that in humans. We hypothesized that a better prediction from rodent data could be achieved when a tracer is evaluated under P-gp inhibition. Consequently, we compared the performance of eight neuroreceptor tracers in rats with and without P-gp inhibition including a specific binding blockade. This data set was then used to predict the binding of these eight tracers in pigs.

Methods: PET tracers targeting serotonin $5-\mathrm{HT}_{2 \mathrm{~A}}$ receptors $\left(\left[{ }^{18} \mathrm{~F}\right] \mathrm{MH} . \mathrm{MZ},\left[{ }^{18} \mathrm{~F}\right]\right.$ Altanserin, $\left[{ }^{11} \mathrm{C}\right] \mathrm{Cimbi}-36,\left[{ }^{11} \mathrm{C}\right]$ Pimavanserin), serotonin $5-\mathrm{HT}_{7}$ receptors $\left(\left[{ }^{11} \mathrm{C}\right] \mathrm{Cimbi}-701,\left[{ }^{11} \mathrm{C}\right] \mathrm{Cimbi}-717\right.$ and $\left.\left[{ }^{11} \mathrm{C}\right] \mathrm{BA}-10\right)$ and dopamine $\mathrm{D}_{2 / 3}$ receptors $\left(\left[{ }^{18} \mathrm{~F}\right]\right.$ Fallypride) were used in the study. The brain uptake and target-specific binding of these PET radiotracers were evaluated in rats with and without inhibition of P-gp. Rat data were subsequently compared to the results obtained in pigs.

Results: Without P-gp inhibition, the amount of target-specific binding in the rat brain was sufficient to justify further translation for three out of eight evaluated tracers. With P-gp inhibition, results for five out of eight tracers justified further translation. The performance in pigs could correctly be predicted for six out of eight tracers when rat data obtained under P-gp inhibition were used, compared to four out of eight tracers without P-gp inhibition.
\end{abstract}

Conclusions: P-gp strongly affects the uptake of PET tracers in rodents, but false prediction outcomes can be reduced by evaluating a tracer under P-gp inhibition.

Keywords: P-gp, Efflux transporter, PET, Rodents, Pigs, Rats, Translation

*Correspondence: matthias.herth@sund.ku.dk

†Vladimir Shalgunov and Mengfei Xiong contributed equally to this work

${ }^{1}$ Department of Drug Design and Pharmacology, Faculty of Health and Medical Sciences, University of Copenhagen, Jagtvej 160,

2100 Copenhagen, Denmark

Full list of author information is available at the end of the article

\section{Background}

Positron emission tomography (PET) is a powerful molecular imaging technique that has earned an established position in the clinic as a diagnostic tool. It provides a combination of high sensitivity, tissue penetration and quantitativity that is unmatched by any other molecular imaging technique [1]. Apart from its clinical applications, PET is also frequently applied in 
translational research and drug development to noninvasively quantify biological targets, dose-occupancy relationships or therapeutic response [2, 3].

During preclinical development of novel PET tracers, it is important to use animals that represent human physiology as closely as possible. Rodents are usually tested first, for a number of reasons including lower costs compared to larger animals and the availability of disease models [4]. Compared to other species, rodents have been demonstrated to have increased brain expression of the efflux transporter, P-glycoprotein (P-gp), both in absolute terms and relative to other drug efflux transporters $[5,6]$. P-gp is an ATP-dependent efflux pump, localized at the luminal side of the brain capillary endothelium which forms the blood-brain barrier (BBB). Substrates of P-gp are pumped out into the lumen of the brain capillaries and thus removed from the brain tissue [7]. P-gp activity is known to be a major factor limiting the brain uptake of PET tracers in rodents $[8,9]$. If tracers for central nervous system (CNS) targets are initially evaluated in rodents and show low brain uptake, they could be de-selected for further translation, even though they would have worked in higher species, including humans.

We have previously demonstrated that the brain uptake of two PET tracers used for brain receptor imaging, $\left[{ }^{11} \mathrm{C}\right] \mathrm{GR} 205171$ and $\left[{ }^{18} \mathrm{~F}\right]$ Altanserin, was three-sixfold lower in rats than in humans, which is unsatisfactorily low [10]. In the same study, the uptake of $\left[{ }^{18} \mathrm{~F}\right]$ Altanserin in the minipig brain was 3.8 -fold higher than in the rat brain, apparently due to a lower P-gp activity in pigs. Detecting brain uptake of this magnitude during initial evaluation of a tracer would warrant further translation to humans.
In this study, we investigate if rodents generally display higher efflux transporter activity than pigs by studying the brain uptake of eight structurally different PET tracers in both rodents and pigs. Furthermore, we propose an experimental design which accounts for elevated P-gp activity in rodents and facilitates the translation of tracers from rodents to higher species. Specifically, we supplement the traditional evaluation of tracer uptake at baseline and after selective target block with concomitant inhibition of P-gp activity.

Figure 1 summarizes our set-up. In short, rats were scanned under four experimental conditions: drug-naïve or "baseline" (1), target block (2), P-gp inhibition (3) and target block combined with P-gp inhibition (4). The advantage of this set-up is that, in addition to assessing the specific binding of the tracer, it determines whether the tracer is a P-gp substrate or not. Importantly, this setup is compatible with the higher-throughput scanning approach earlier reported by us [11], where four rats are scanned simultaneously in a clinical PET scanner. Thus, all four experimental conditions can be evaluated in a single scan.

Eight PET tracers for three different receptor systems were used in this study. Serotonin $5-\mathrm{HT}_{2 \mathrm{~A}}$ receptor tracers $\left[{ }^{18} \mathrm{~F}\right]$ Altanserin, $\left[{ }^{11} \mathrm{C}\right] \mathrm{Cimbi}-36, \quad\left[{ }^{11} \mathrm{C}\right]$ Pimavanserin and $\left[{ }^{18} \mathrm{~F}\right] \mathrm{MH} . \mathrm{MZ}$, serotonin $5-\mathrm{HT}_{7}$ receptor tracers $\left[{ }^{11} \mathrm{C}\right]$ Cimbi-701, $\left[{ }^{11} \mathrm{C}\right] \mathrm{Cimbi}-717$ and $\left[{ }^{11} \mathrm{C}\right] \mathrm{BA}-10$ and dopamine $D_{2 / 3}$ receptor tracer $\left[{ }^{18} \mathrm{~F}\right]$ Fallypride were studied.

Results of the tracer evaluation via both the traditional workflow (baseline and target block conditions) and the new workflow (P-gp inhibition alone and combined with target block) were used to predict the performance of the same tracer in pigs. The prediction algorithm is illustrated in Additional file 1: Fig. S1. We hypothesized

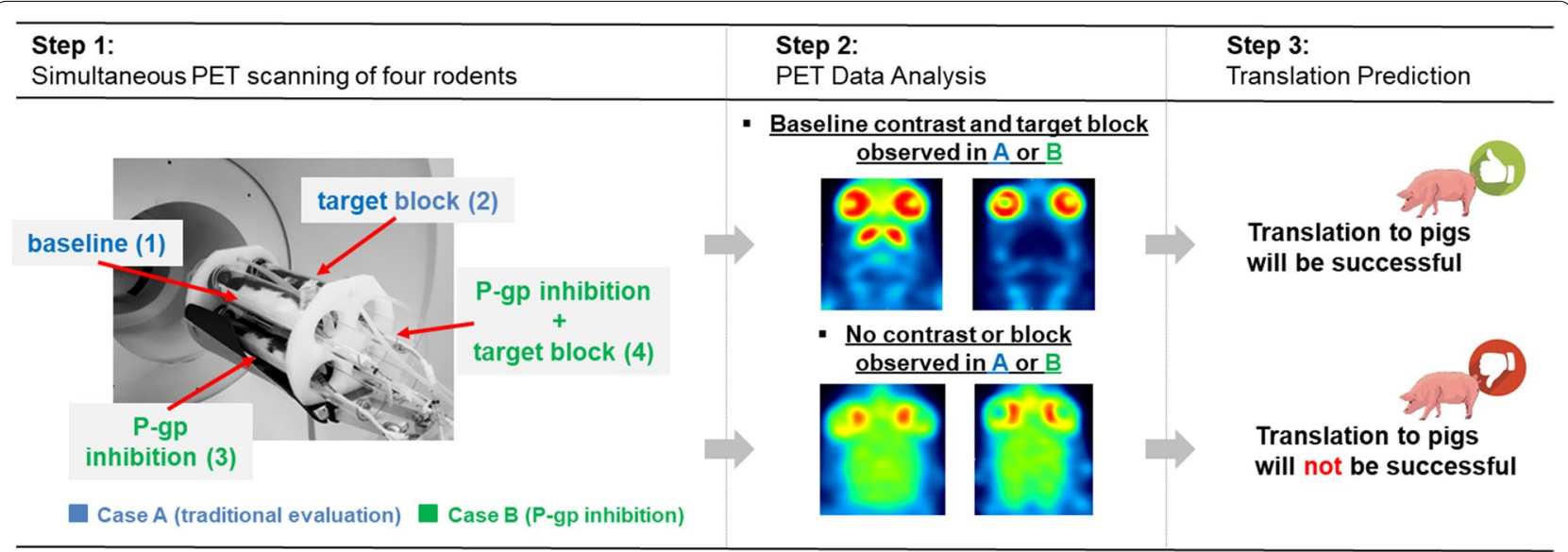

Fig. 1 Tracer evaluation strategy. Step 1 and 2: Traditionally, specific binding can be determined by comparing tracer uptake at baseline and after target block (Case A). This work proposes to perform the same two experiments with simultaneous inhibition of P-gp (Case B). Step 3: If specific binding is observed in Case A or B, a successful translation from rodent to pig is predicted 
that additional evaluation of a tracer's P-gp dependency would give a better prediction of its performance in pigs and ultimately in humans than the traditional workflow.

\section{Methods}

Radiochemistry

$\left[{ }^{18} \mathrm{~F}\right]$ Altanserin, $\left[{ }^{11} \mathrm{C}\right] \mathrm{Cimbi}-36,\left[{ }^{11} \mathrm{C}\right]$ Pimavanserin, $\left[{ }^{18} \mathrm{~F}\right]$ MH.MZ, $\left[{ }^{18} \mathrm{~F}\right]$ Fallypride, $\left[{ }^{11} \mathrm{C}\right]$ Cimbi-701, $\left[{ }^{11} \mathrm{C}\right] \mathrm{Cimbi}-$ 717 and $\left[{ }^{11} \mathrm{C}\right] \mathrm{BA}-10$ were synthesized as previously reported [12-19]. Chemical structures of all compounds are displayed in the Additional file (Additional file 1: Fig. S2).

\section{Animals}

Long-Evans WT (or Sprague-Dawley in the case of $\left[{ }^{18} \mathrm{~F}\right]$ Altanserin) female rats of $200-300 \mathrm{~g}$ (8-10 weeks) (Charles River, Calco, Italy) were housed in groups of 2-3 animals per cage in a climate-controlled rodent facility with a 12-h light/dark cycle. The animals had free access to water and were fed ad libitum. All procedures were conducted in accordance with the European Commission's Directive 2010/63/EU, FELASA and ARRIVE guidelines for animal research and, with approval from The Danish Council for Animal Ethics (license numbers: 2017-15-0201-01283, 2012-15-2934-00156, 2007-5611320) as well as the Department of Experimental Medicine, University of Copenhagen.

\section{Pig PET experiments}

Description of PET experiments in pigs and analysis of obtained data can be found in the Additional file 1.

\section{Rat PET scanning protocol}

On the day of scanning, rats were transported to the scanner at least one hour prior to the experiment. Isoflurane, $3-3.5 \%$ in $0.6 \%$ oxygen, was used to induce anaesthesia, while anaesthesia was maintained with $2.0-2.5 \%$ isoflurane during the scans. The PET tracers were administered as intravenous (i.v.) bolus injections via tail vein catheters (BD Neoflon 25G, Stockholm, Sweden) at the beginning of the scan with doses being between 5-20 MBq. The rats were subsequently scanned in the High-Resolution Research Tomograph (HRRT) scanner (Siemens AG, Munich, Germany) using a custom-made $2 \times 2$ rat holder, which enabled simultaneous scanning of four rats (Fig. 1) [11]. The animals were scanned for either $60 \mathrm{~min}\left({ }^{11} \mathrm{C}\right)$ or $90 \mathrm{~min}\left({ }^{18} \mathrm{~F}\right)$, followed by a transmission scan at speed 10 (acquisition time approximately $6 \mathrm{~min}$ ). The animals were scanned at baseline (no pre-treatment before tracer injection) and after receiving P-gp inhibition with or without target block. Details of inhibition and blocking regimens are described in Table 1. For combined inhibition and target block scans, rats were pre-treated with the P-gp inhibitor elacridar (5 mg/kg, Carbosynth, Compton, UK) and the $5-\mathrm{HT}_{7}$ receptor antagonist SB-269970 (3 mg/kg, Tocris Bioscience, Abingdon, UK), the sigma and dopamine $\mathrm{D}_{2 / 3}$ receptor antagonist haloperidol $(1 \mathrm{mg} / \mathrm{kg}$, Janssen-Cilag, Birkerød, Denmark) or the $5-\mathrm{HT}_{2 \mathrm{~A}}$ receptor antagonist ketanserin (3 mg/kg, Sigma-Aldrich, Saint Louis, Missouri, USA). Elacridar was given $30 \mathrm{~min}$ prior to tracer injection through the intravenous catheter, and receptor blocking drugs were given 15 min before tracer injection. Chosen dosages and pre-treatment intervals were based on literature data [20-23].

Studies with $\left[{ }^{18} \mathrm{~F}\right]$ Altanserin were performed in a MicroPET Focus 120 scanner (Siemens Medical Solutions, Malvern, PA, USA). Hyponorm/midazolam (VetaPharma Ltd., Leeds, UK/Hameln Pharmaceuticals, Hameln, Germany) was used as anaesthesia. The rats received $11 \pm 2 \mathrm{MBq}$ of the tracer as a bolus injection. Three of the rats were administered with $22.5 \mathrm{mg} /$ $\mathrm{kg}$ bolus of cyclosporin A (Sandimmun, Novartis, Basel, Switzerland) followed by a constant infusion of $7.5 \mathrm{mg} /$

Table 1 Target blocking drugs, P-gp inhibitors and PET image summation timespan for rat PET experiments

\begin{tabular}{|c|c|c|c|c|c|}
\hline Tracer & Target blocking drug & Dose (mg/kg) & P-gp inhibitor & Dose & $\begin{array}{l}\text { Time span } \\
\text { for image } \\
\text { summation ( } \mathrm{min})\end{array}$ \\
\hline$\left[{ }^{18} \mathrm{~F}\right] \mathrm{MH} . \mathrm{MZ}$ & Ketanserin & 3 & Elacridar & 5 & $5-90$ \\
\hline$\left[{ }^{18} \mathrm{~F}\right]$ Altanserin & Ketanserin & 3 & Cyclosporin A & $22.5^{\mathrm{a}}$ & $5-90$ \\
\hline$\left[{ }^{11} \mathrm{C}\right]$ Pimavanserin & Ketanserin & 3 & Elacridar & 5 & $5-60$ \\
\hline$\left[{ }^{11} \mathrm{C}\right] \mathrm{Cimbi}-36$ & Ketanserin & 3 & Elacridar & 5 & $5-60$ \\
\hline$\left[{ }^{11} \mathrm{C}\right] \mathrm{Cimbi}-717$ & SB269970 & 3 & Elacridar & 5 & $2-60$ \\
\hline$\left[{ }^{11} \mathrm{C}\right] \mathrm{Cimbi}-701$ & SB269970 & 3 & Elacridar & 5 & $2-60$ \\
\hline$\left[{ }^{11} \mathrm{C}\right] \mathrm{BA}-10$ & SB269970 & 3 & Elacridar & 5 & $30-60$ \\
\hline$\left[{ }^{18} \mathrm{~F}\right]$ Fallypride & Haloperidol & 1 & Elacridar & 5 & $5-90$ \\
\hline
\end{tabular}

a After bolus injection of $22.5 \mathrm{mg} / \mathrm{kg}$ cyclosporin A, rats received constant infusion of $7.5 \mathrm{mg} / \mathrm{kg} / \mathrm{h}$ 
$\mathrm{kg} / \mathrm{h}$, starting $20-25$ min before radiotracer administration, as previously described [10].

\section{Rat PET image reconstruction}

For HRRT scans (all tracers except $\left[{ }^{18} \mathrm{~F}\right]$ Altanserin), 60-min list-mode PET data were transformed into 33 dynamic frames $(6 \times 10,6 \times 20,6 \times 60,8 \times 120$, and $7 \times 300$ s), while 90 -min list-mode PET data were transformed into 35 dynamic frames $(6 \times 10,8 \times 30,5 \times 60$, and $16 \times 300 \mathrm{~s})$. Attenuation maps were reconstructed from transmission scans using maximum a posteriori algorithm for transmission data (MAP-TR) with human head $(\mathrm{HH})$ segmentation/thresholding scans [11]. All images were reconstructed using ordinary Poisson 3D ordered subset expectation maximization (OP-OSEM3D) algorithm with point spread function modelling. PET image frames consisted of 207 planes of $256 \times 256$ voxels of $1.22 \times 1.22 \times 1.22 \mathrm{~mm}$. $\left[{ }^{18} \mathrm{~F}\right]$ Altanserin scans were performed on the Focus 120 camera. Ninety-minute list-mode PET data were transformed into 25 dynamic frames $(10 \times 30,5 \times 120,5 \times 30$, and $5 \times 600 \mathrm{~s})$ and reconstructed using the filtered back-projection method. Reconstructed PET image frames consisted of 95 planes of $128 \times 128$ voxels of $0.87 \times 0.87 \times 0.80 \mathrm{~mm}$.

\section{Quantification of rat PET data}

For data analysis, the software PMOD 3.7 (PMOD Technologies, Zürich, Switzerland) was used. Summed PET images were generated based on all counts recorded in the time intervals specified in Table 1 . Images were then aligned to a standardized MRI-based atlas of the rat brain [24] from where pre-defined regions of interest (ROIs) were extracted. Regions known to possess high densities of relevant receptors were selected as target ROIs: medial prefrontal cortex (mPFC) and frontal cortex (FC) for $5-\mathrm{HT}_{2 \mathrm{~A}}$ receptor PET tracers [25], thalamus (Tha) for $5-\mathrm{HT}_{7}$ receptor PET tracers [16] and striatum (Str) for dopamine $\mathrm{D}_{2 / 3}$ receptor tracer [26]. Cerebellum region $(\mathrm{Cb})$, having low densities of receptors targeted by all investigated tracers, was chosen as a reference region (Additional file 1: Fig. S3). In addition, whole brain (Wb) ROI was chosen to monitor overall tracer penetration into the brain. The time-activity curves (TACs) for target ROIs were extracted from the PET images, and the activity was converted into standardized uptake values (SUV). SUV, expressed in $\mathrm{g} / \mathrm{mL}$, is equal to the concentration of radioactivity measured in the ROI divided by the injected radioactivity dose per body weight. Area under the curve (AUC) values were calculated from the TACs using GraphPad Prism 7 (GraphPad Software, California, USA) and expressed in $\mathrm{min} \times \mathrm{g} / \mathrm{mL}$. As scanning durations were different for ${ }^{11} \mathrm{C}$-labelled and ${ }^{18} \mathrm{~F}$-labelled tracers (60 min and $90 \mathrm{~min}$, respectively), AUC values of
${ }^{18} \mathrm{~F}$-labelled tracers were calculated for both the full duration and the first $60 \mathrm{~min}$ of the scan.

\section{Rat data analysis}

Apparent target-specific binding of the tracers in the target regions was expressed as specific binding ratios (SBR), which were calculated from mean full scan length AUC values applying Eq. 1; cerebellum was used as a reference region for all tracers. Changes in apparent specific binding of the tracers in response to target receptor blockade were calculated from SBR values using Eq. 2; SBR changes were calculated for "baseline-target block" and "P-gp inhibition alone-combined P-gp inhibition and target block" condition pairs. Changes in tracer uptake in the target-rich region in response to P-gp inhibition were calculated from mean AUC values for the first $60 \mathrm{~min}$ of the scan as shown in Eq. 3.

$$
\begin{aligned}
& \mathrm{SBR}=\frac{\mathrm{AUC}_{\text {targetROI }}-\mathrm{AUC}_{\text {referenceROI }}}{\mathrm{AUC}_{\text {referenceROI }}} \\
& \% \mathrm{SBR} \text { change }=100 \% \times \frac{\mathrm{SBR}_{\text {baseline }}-\mathrm{SBR}_{\text {block }}}{\mathrm{SBR}_{\text {baseline }}}
\end{aligned}
$$

$$
\text { \%AUCchange }=100 \% \times \frac{\mathrm{AUC}_{\text {Pgp inhibition }}^{60 \text { min }}-\mathrm{AUC}_{\text {baseline }}^{60 \text { min }}}{\mathrm{AUC}_{\text {baseline }}^{60 \text { melin }}}
$$

Evaluation of a tracer was considered successful if (whether with or without P-gp inhibition) the tracer showed an SBR value of at least 0.15 (15\% higher uptake in the target region relative to reference region), and this SBR value decreased by at least $30 \%$ under target block condition.

\section{Results}

Of the four $5-\mathrm{HT}_{2 \mathrm{~A}}$ receptor tracers investigated, only $\left[{ }^{18} \mathrm{~F}\right] \mathrm{MH} . \mathrm{MZ}$ showed substantial uptake in the rat brain at baseline: AUC for the target receptor-rich mPFC was $60 \pm 5 \mathrm{~min} \times \mathrm{g} / \mathrm{mL}$ (here and further AUC values refer to the first $60 \mathrm{~min}$ of the scan unless stated otherwise; full scan length AUC values for all tracers, ROIs and experimental conditions are presented in Additional file 1: Table S1; numbers of rats scanned per experimental condition are shown in Additional file 1: Table S2). Baseline SBR for mPFC equalled 0.71. Pre-treatment with ketanserin, a $5-\mathrm{HT}_{2 \mathrm{~A}}$ receptor antagonist, decreased SBR to 0.02 ( $-97 \%$ change). Under P-gp inhibition with elacridar, the AUC for the $\mathrm{mPFC}$ rose to $147 \mathrm{~min} \times \mathrm{g} /$ $\mathrm{mL}(+143 \%)$, and the SBR value for the mPFC reached 1.04. Combining target blockade with P-gp inhibition decreased the SBR to $0.04(-96 \%)$. Thus, the $5-\mathrm{HT}_{2 \mathrm{~A}}$ receptor-specific binding and the blocking of it were 
clearly detectable both with and without P-gp inhibition for $\left[{ }^{18}\right.$ F]MH.MZ (Fig. 2 and Additional file 1: Fig. S4).

In contrast, $\left[{ }^{18} \mathrm{~F}\right]$ Altanserin, $\left[{ }^{11} \mathrm{C}\right]$ Pimavanserin and $\left[{ }^{11} \mathrm{C}\right] \mathrm{Cimbi}-36$ showed low brain penetration at baseline, with AUC values for mPFC (FC for $\left[{ }^{18} \mathrm{~F}\right]$ Altanserin) in the range of $23-36 \mathrm{~min} \times \mathrm{g} / \mathrm{mL}$ (Fig. 2 and Additional file 1: Fig. S4). SBR values were 0.33 for $\left[{ }^{18} \mathrm{~F}\right]$ Altanserin, 0.02 for $\left[{ }^{11} \mathrm{C}\right]$ Pimavanserin and 0.18 for $\left[{ }^{11} \mathrm{C}\right] \mathrm{Cimbi}-36$. After ketanserin pre-treatment, $\left[{ }^{11} \mathrm{C}\right] \mathrm{Cimbi}-36$ SBR fell to $0.10(-44 \%)$, while SBR values for $\left[{ }^{18} \mathrm{~F}\right]$ Altanserin and $\left[{ }^{11} \mathrm{C}\right]$ Pimavanserin actually grew to $0.89(+172 \%)$ and $0.04(+110 \%)$, respectively. Thus, for these three tracers,

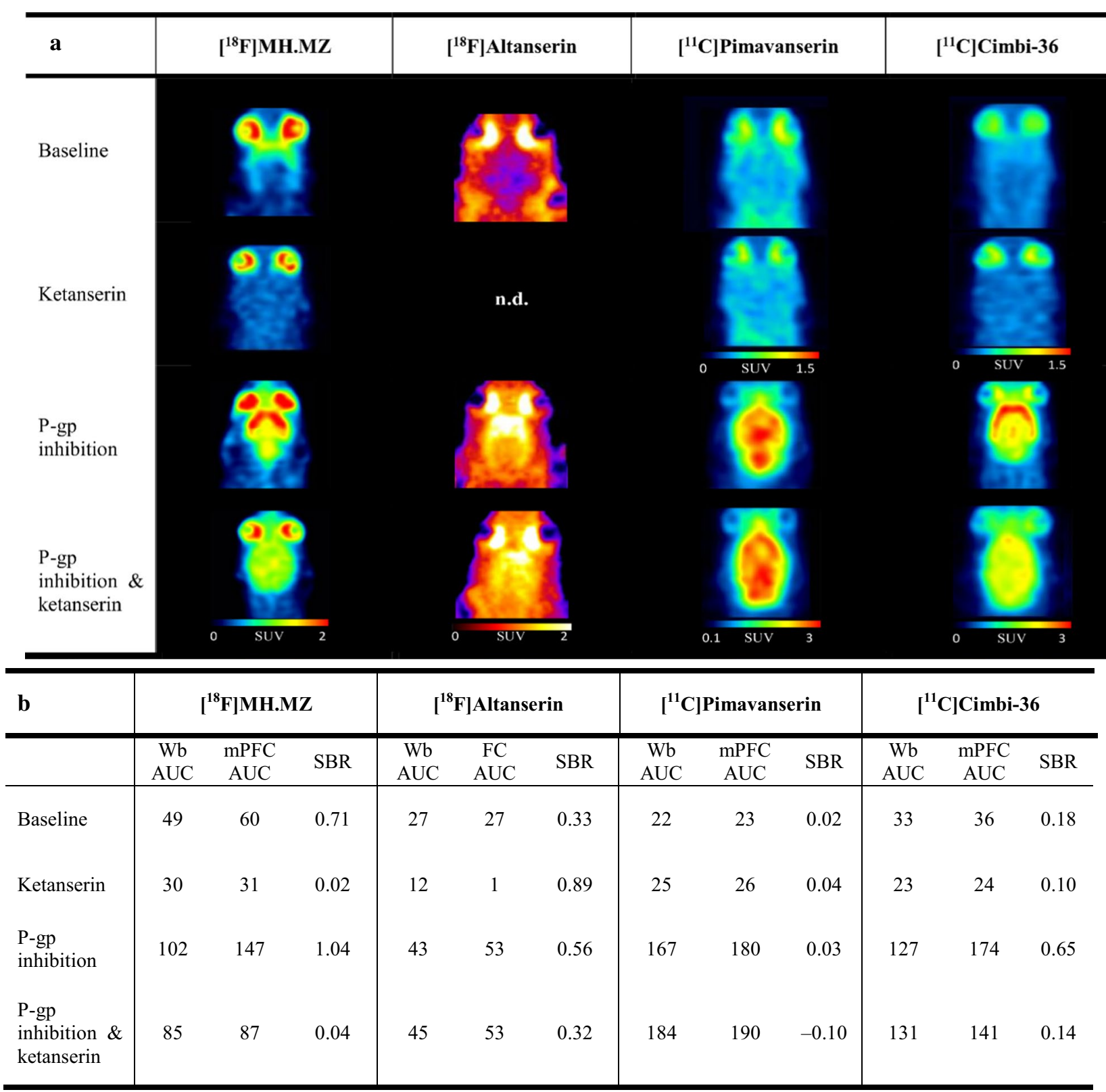

Fig. 2 PET images (a), AUC and SBR values (b) for the $5-\mathrm{HT}_{2 \mathrm{~A}}$ receptor tracers $\left.\left[{ }^{18} \mathrm{~F}\right] \mathrm{MH} . \mathrm{MZ},{ }^{[8} \mathrm{F}\right] \mathrm{Altanserin},\left[{ }^{11} \mathrm{C}\right]$ Pimavanserin and $\left[{ }^{11} \mathrm{C}\right] \mathrm{Cimbi}-36$. Representative horizontal rat PET images, 60-min AUC values ( $\mathrm{min} \times \mathrm{g} / \mathrm{mL}$ ) and SBR values are shown for baseline, target block with ketanserin, efflux transporter inhibition and combined P-gp inhibition — target block conditions (see Table 1 for details on drug dosing and PET image summation). n.d.= summed PET image could not be generated. Numbers of rats scanned per experimental condition are shown in Additional file 1: Table S2. Wb whole brain, MPFC medial prefrontal cortex, FC frontal cortex, AUC area under the curve, SBR specific binding ratios, $P$-gP P-glycoprotein 
blockable target-specific binding could only be detected for $\left[{ }^{11} \mathrm{C}\right] \mathrm{Cimbi}-36$.

After P-gp inhibition, mPFC AUC values for $\left[{ }^{18} \mathrm{~F}\right]$ Altanserin, $\left[{ }^{11} \mathrm{C}\right]$ Pimavanserin and $\left[{ }^{11} \mathrm{C}\right] \mathrm{Cimbi}-36$ increased to $53 \mathrm{~min} \times \mathrm{g} / \mathrm{mL}(+93 \%), 180 \mathrm{~min} \times \mathrm{g} / \mathrm{mL}(+689 \%)$ and $174 \mathrm{~min} \times \mathrm{g} / \mathrm{mL}(+391 \%)$, while SBR values reached 0.56 , 0.03 and 0.65 , respectively. Ketanserin blockade combined with P-gp inhibition resulted in SBR values of 0.32 $(-42 \%)$ for $\left[{ }^{18} \mathrm{~F}\right]$ Altanserin and $0.14(-79 \%)$ for $\left[{ }^{11} \mathrm{C}\right]$ Cimbi-36. For $\left[{ }^{11} \mathrm{C}\right]$ Pimavanserin, AUC in the cerebellum after combined ketanserin and elacridar pre-treatment was greater than AUC in the mPFC, resulting in a negative SBR value of -0.10 . However, a change in SBR from 0.03 to -0.10 , although high in relative terms $(-395 \%)$, can hardly be interpreted as a sign of target-specific binding because both values are very low.

All in all, for $\left[{ }^{18} \mathrm{~F}\right]$ Altanserin, $5-\mathrm{HT}_{2 \mathrm{~A}}$ receptor-specific binding and the blocking effect became observable after P-gp inhibition, for $\left[{ }^{11} \mathrm{C}\right] \mathrm{Cimbi}-36$ the use of P-gp inhibition led to an amplification of both apparent specific binding at baseline and the blocking effect, while $\left[{ }^{11} \mathrm{C}\right]$ Pimavanserin did not show any sign of specific $5-\mathrm{HT}_{2 \mathrm{~A}}$ receptor binding either with or without $\mathrm{P}$-gp inhibition (Fig. 2a).

Among tracers targeting $5-\mathrm{HT}_{7}$ receptors, we investigated $\left[{ }^{11} \mathrm{C}\right] \mathrm{Cimbi}-717,\left[{ }^{11} \mathrm{C}\right] \mathrm{Cimbi}-701$ and $\left[{ }^{11} \mathrm{C}\right] \mathrm{BA}-10$ $[16,17,27]$. At baseline, all tracers showed low AUC values between 30 and $43 \mathrm{~min} \times \mathrm{g} / \mathrm{mL}$ in the $5-\mathrm{HT}_{7}$ receptor-rich thalamus (Fig. 3 and Additional file 1: Fig. S5). Baseline thalamic SBR values were also low for all three tracers, varying from -0.01 for $\left[{ }^{11} \mathrm{C}\right] \mathrm{Cimbi}-701$ to 0.10 for $\left[{ }^{11} \mathrm{C}\right] \mathrm{Cimbi}-701$. After pre-treatment with the $5-\mathrm{HT}_{7}$ selective antagonist SB-269970, the SBR values for $\left[{ }^{11} \mathrm{C}\right]$ Cimbi-701 and $\left[{ }^{11} \mathrm{C}\right] \mathrm{BA}-10$ increased, while for $\left[{ }^{11} \mathrm{C}\right]$ Cimbi-717 the SBR value decreased to 0.09 (at $-5 \%$ ). Thalamic AUC values reached $62 \mathrm{~min} \times \mathrm{g} / \mathrm{mL}(+47 \%)$ for $\left[{ }^{11} \mathrm{C}\right] \mathrm{Cimbi}-717,142 \mathrm{~min} \times \mathrm{g} / \mathrm{mL}(+277 \%)$ for $\left[{ }^{11} \mathrm{C}\right]$ Cimbi-701 and $65 \mathrm{~min} \times \mathrm{g} / \mathrm{mL}(+121 \%)$ for $\left[{ }^{11} \mathrm{C}\right] \mathrm{BA}-10$ after P-gp inhibition with elacridar. Respective SBR values were $0.14,0.18$ and 0.16 . Simultaneous inhibition of P-gp and blocking of the $5-\mathrm{HT}_{7}$ receptor decreased $\left[{ }^{11} \mathrm{C}\right] \mathrm{BA}-10$ SBR to $0.09(-44 \%)$, while SBRs for $\left[{ }^{11} \mathrm{C}\right]$ Cimbi-717 and $\left[{ }^{11} \mathrm{C}\right] \mathrm{Cimbi}-701$ actually increased to 0.21 $(+46 \%)$ and $0.22(+23 \%)$, respectively. In summary, specific binding could only be detected for $\left[{ }^{11} \mathrm{C}\right] \mathrm{BA}-10$ after P-gp inhibition.

The dopamine $\mathrm{D}_{2 / 3}$ receptor ligand $\left[{ }^{18} \mathrm{~F}\right]$ Fallypride was included into the study as a non-serotonergic tracer. Baseline striatal AUC equalled $95 \mathrm{~min} \times \mathrm{g} / \mathrm{mL}$. Striatal SBR was 3.11 at baseline and fell to $0.01(-100 \%)$ after haloperidol pre-treatment (Fig. 4 and Additional file 1: Fig. S5). After P-gp inhibition, striatal AUC rose to $244 \mathrm{~min} \times \mathrm{g} / \mathrm{mL}(+158 \%)$, and SBR reached 4.07 .
Combined P-gp inhibition and target $\left(\mathrm{D}_{2 / 3}\right)$ block decreased striatal SBR to 0.22 (-95\%). Therefore, targetspecific binding was clearly visible both without and with P-gp inhibition.

Evaluation of $\left[{ }^{18} \mathrm{~F}\right] \mathrm{MH} . \mathrm{MZ}, \quad\left[{ }^{18} \mathrm{~F}\right]$ Altanserin, $\quad\left[{ }^{11} \mathrm{C}\right]$ Pimavanserin, $\left[{ }^{11} \mathrm{C}\right] \mathrm{Cimbi}-36,\left[{ }^{11} \mathrm{C}\right] \mathrm{Cimbi}-717$ and $\left[{ }^{11} \mathrm{C}\right]$ Cimbi-701 in pigs was reported previously $[15,19,27$, 28]. Time-activity curves for $\left[{ }^{11} \mathrm{C}\right] \mathrm{BA}-10$ and $\left[{ }^{18} \mathrm{~F}\right]$ Fallypride in pig brain are presented in Additional file 1: Figs. S6 and S7, respectively.

\section{Discussion}

In this work, we propose a higher-throughput approach to improve the translation of CNS PET tracers from rodents to higher species. Our data suggest that one of the main factors limiting translation of CNS tracers from rats to larger animals is the higher activity of efflux pumps, including P-gp, in rats. We used cyclosporine A and elacridar to inhibit the action of P-gp, the dominant drug efflux transporter in the rodent brain and study the influence of P-gp on the accumulation of a set of eight tracers [5]. Cyclosporine A is a selective P-gp inhibitor, while elacridar inhibits both P-gp and BCRP (breast cancer resistance protein) efflux pumps [29]. Within our data set, all investigated tracers showed higher brain uptake in rats when the action of P-gp was inhibited. The smallest increase in target-rich region AUC values after P-gp inhibition was observed for $\left[{ }^{11} \mathrm{C}\right] \mathrm{Cimbi}-717(47 \%)$ and $\left[{ }^{18} \mathrm{~F}\right]$ Altanserin (93\%), while for all other tracers, AUC values increased by $100-700 \%$. Brain uptake of $\left[{ }^{18} \mathrm{~F}\right]$ Altanserin was previously reported to increase 2.6 -fold (by $160 \%$ ) in response to P-gp inhibition [10], which is higher but still comparable to the results obtained in this work $(+93 \%)$, using the same P-gp inhibition condition. Higher increase reported in [10] could have been the consequence of a higher body weight of the rats used for the experiments ( $370 \mathrm{~g}$ vs $200-300 \mathrm{~g}$ in this work). It should be noted that all compounds evaluated by us are secondary and/or tertiary amines, which tend to be P-gp substrates [30, 31]. However, an amino group is often present in CNS PET tracers.

In the absence of P-gp inhibition, only $\left[{ }^{18} \mathrm{~F}\right] \mathrm{MH} . \mathrm{MZ}$, $\left[{ }^{11} \mathrm{C}\right] \mathrm{Cimbi}-36$ and $\left[{ }^{18} \mathrm{~F}\right]$ Fallypride showed preferential accumulation (SBR values of $>0.15$ ) in target-rich regions and more than $30 \%$ reduction in SBR values after a selective target block (Figs. 2 and 4 ). $\left[{ }^{18} \mathrm{~F}\right]$ Altanserin demonstrated a decent SBR value (0.33) at baseline without P-gp inhibition, but ketanserin pre-treatment led to a drastic decrease of tracer uptake in both frontal cortex and cerebellum, with uptake in the cerebellum falling even more drastically (Additional file 1: Table S1). As a consequence, $\left[{ }^{18} \mathrm{~F}\right]$ Altanserin's SBR after target blockade was higher compared to baseline conditions. Likewise, brain 


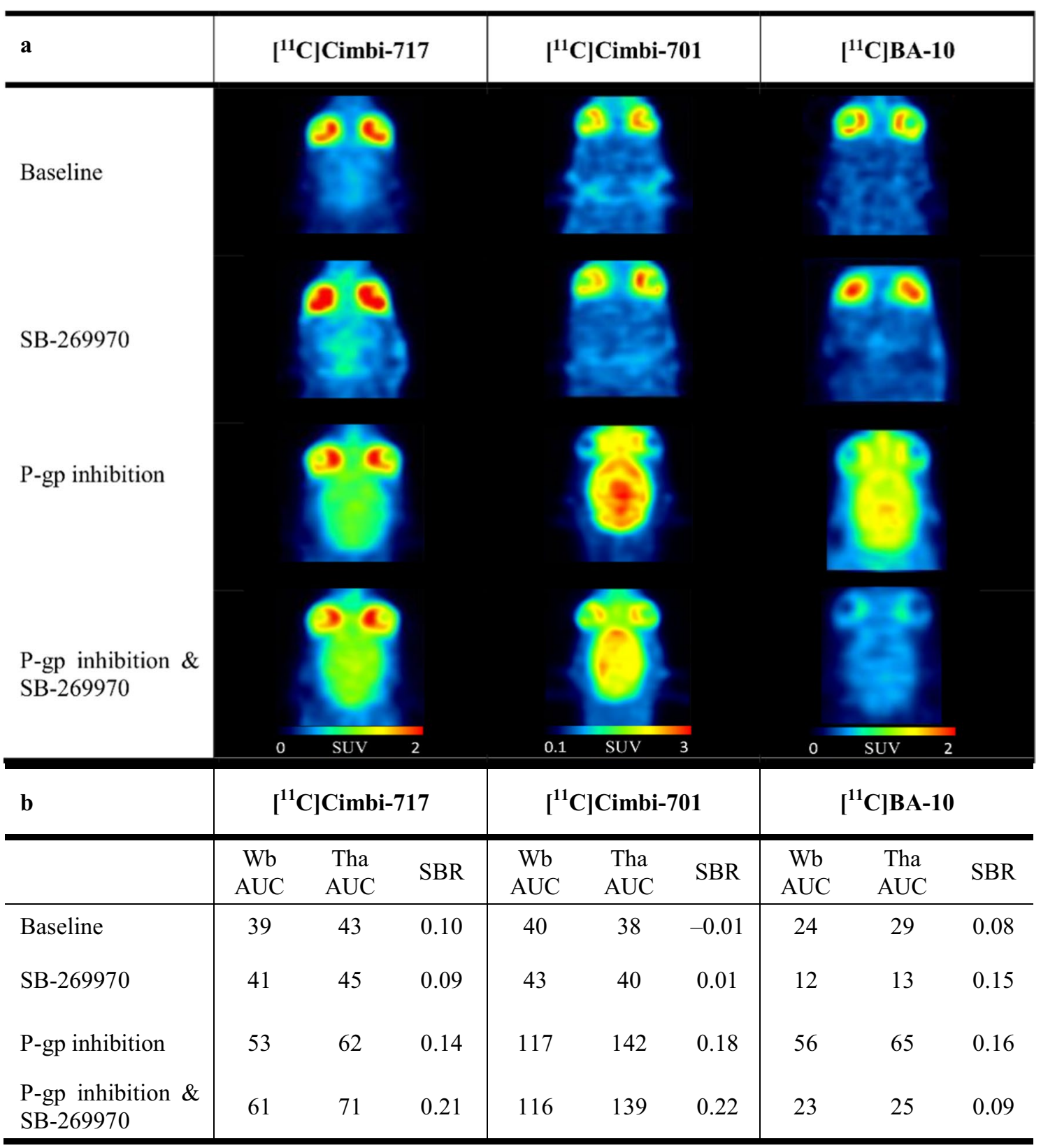

Fig. 3 PET images (a), AUC and SBR values (b) for the $5-H T$, receptor tracers $\left[{ }^{11} \mathrm{C}\right] \mathrm{Cimbi}-717,\left[{ }^{11} \mathrm{C}\right] \mathrm{Cimbi}-701$, and $\left[{ }^{11} \mathrm{C}\right] \mathrm{BA}-10$. Representative horizontal rat PET images, 60-min AUC values $(\mathrm{min} \times \mathrm{g} / \mathrm{mL}$ ) and SBR values are shown for baseline, target block with SB-269970, P-gp inhibition with elacridar and combined P-gp inhibition — target block conditions (see Table 1 for details on drug dosing and PET image summation). Numbers of rats scanned per experimental condition are shown in Additional file 1: Table S2. Wb whole brain, Tha thalamus, Cb cerebellum, AUC area under the curve, SBR specific binding ratios, P-gp P-glycoprotein

uptake in the reference ROI decreased more than in the target ROI in response to target blockade for $\left[{ }^{11} \mathrm{C}\right] \mathrm{BA}-10$. These paradoxical observations may be explained by the hindered diffusion of the tracers across the BBB or their accelerated washout from the brain caused by the vasodilatory [20] or vasoconstrictive [32] properties of the respective blocking drugs (ketanserin and SB-269970). Saturation of P-gp or other efflux transporters by the blocking drugs is an unlikely explanation, because this would have increased the uptake of the tracers in both target and reference ROIs. All in all, further research is required to unequivocally resolve this issue. 


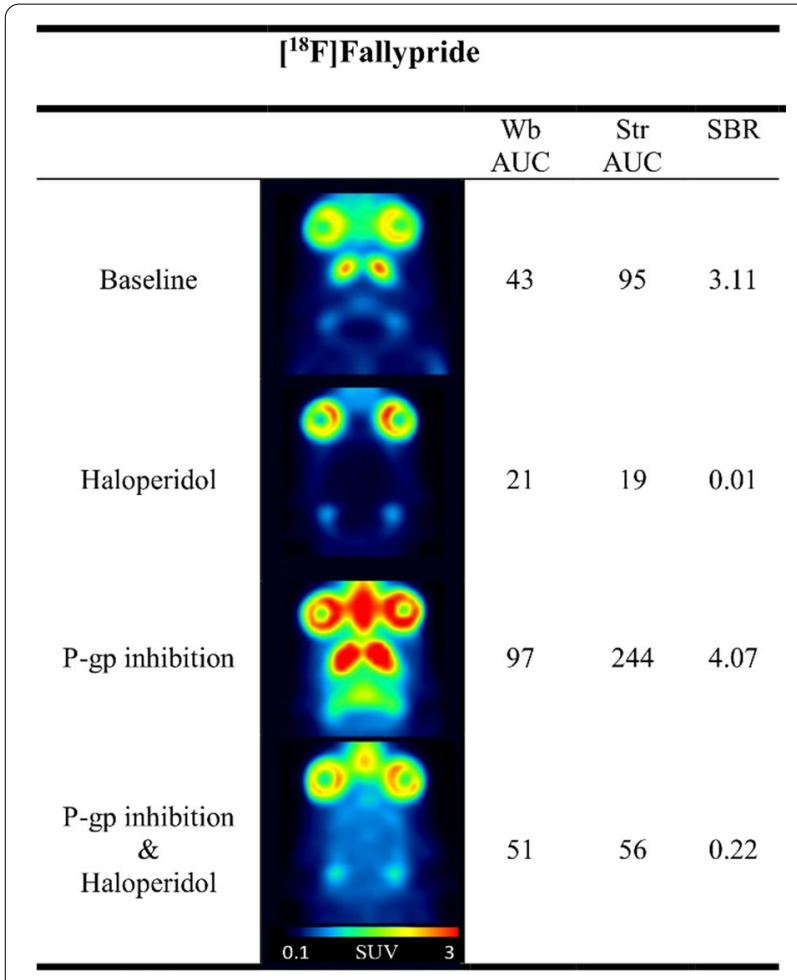

Fig. 4 PET images, AUC and SBR values for the $D_{2 / 3}$ receptor tracer $\left.{ }^{18} \mathrm{~F}\right]$ Fallypride. Representative horizontal rat PET images, 60-min AUC values $(\mathrm{min} \times \mathrm{g} / \mathrm{mL})$ and SBR values are shown for baseline, target block with haloperidol, P-gp inhibition with elacridar and combined P-gp inhibition - target block conditions (see Table 1 for details on drug dosing and PET image summation, $n=2$ ). Str striatum, $C b$ cerebellum, Wb whole brain, AUC area under the curve, SBR specific binding ratios, $P$-gp P-glycoprotein

We hypothesized that the target binding of tracers that are actively transported out of the rat brain can nevertheless be assessed once the increased activity of efflux pumps is inhibited. Therefore, all eight tracers were tested under P-gp inhibition with and without a simultaneous target block. P-gp inhibition led to an increase in baseline SBR values for all tracers (Additional file 1: Fig. S8). Five tracers $\left(\left[{ }^{18} \mathrm{~F}\right] \mathrm{MH} . \mathrm{MZ},\left[{ }^{18} \mathrm{~F}\right]\right.$ Altanserin, $\left[{ }^{11} \mathrm{C}\right]$ Cimbi-36, $\left[{ }^{11} \mathrm{C}\right] \mathrm{BA}-10,\left[{ }^{18} \mathrm{~F}\right]$ Fallypride) showed a pronounced reduction of apparent specific binding in targetrich regions ( $>30 \%$ SBR decrease) in response to target block under these conditions. These included $\left[{ }^{18} \mathrm{~F}\right]$ Altanserin and $\left[{ }^{11} \mathrm{C}\right] \mathrm{BA}-10$, for which no such reduction could be demonstrated using the traditional workflow. For $\left[{ }^{11} \mathrm{C}\right]$ Pimavanserin, $\left[{ }^{11} \mathrm{C}\right] \mathrm{Cimbi}-717$ and $\left[{ }^{11} \mathrm{C}\right] \mathrm{Cimbi}-701$, no receptor-specific binding could be detected under P-gp inhibition: target region SBR values were either too low at baseline $\left(\left[{ }^{11} \mathrm{C}\right]\right.$ Pimavanserin, Fig. 2$)$ or failed to decrease after target receptor blockade $\left(\left[{ }^{11} \mathrm{C}\right] \mathrm{Cimbi}-717\right.$ and $\left[{ }^{11} \mathrm{C}\right]$ Cimbi-701, Fig. 3). For the latter two tracers, their uptake in the target and reference ROIs under P-gp inhibition either did not change in response to target receptor blockade or slightly increased in both ROIs, which led to an increase in SBR (Fig. 3). This could have been caused by the perturbations in the cerebral blood flow due to the pharmacological action of the blocking drug (SB-269970, see above) or by the influx into the brain of the excess of the tracers displaced from $5-\mathrm{HT}_{7}$ receptors in peripheral tissues by the blocking drug.

Based on our data in rats, we predicted whether a tracer would work in pigs or not (see Additional file 1: Fig. S1) and compared these predictions to actual results obtained in pigs, as well as to the evaluation results in humans for those tracers that reached the clinical evaluation stage $\left(\left[{ }^{18} \mathrm{~F}\right] \mathrm{MH} . \mathrm{MZ},\left[{ }^{18} \mathrm{~F}\right]\right.$ Altanserin, $\left[{ }^{11} \mathrm{C}\right] \mathrm{Cimbi}-$ 36 and $\left[{ }^{18} \mathrm{~F}\right]$ Fallypride). Table 2 and Additional file 1 : Table S3 summarize the outcomes. In contrast to rats (Figs. 2 and 3), low brain uptake was not an issue for any of the investigated tracers during evaluation in pigs and humans (Additional file 1: Table S3 and [33-36]). This confirms the notion that rats generally have a highly efficient brain efflux transporter system, which can limit the uptake of tracers in the brain, whereas in larger/higher species the efflux transporter system has less influence on the tracer uptake. Seven out of eight tracers displayed target-specific binding in pigs, i.e. pre-treatment with a specific receptor blocking agent reduced the binding potential $\left(\mathrm{BP}_{\mathrm{ND}}\right)$ of the tracer in the target region (by $30 \%$ or more). For all tracers except $\left[{ }^{11} \mathrm{C}\right] \mathrm{Cimbi}-701$ and $\left[{ }^{11} \mathrm{C}\right]$ Cimbi-717, which had shown specific binding in pigs but not in rats, baseline $\mathrm{BP}_{\mathrm{ND}}$ values in pigs highly correlated with baseline SBR values in rats, both with and without P-gp inhibition (Additional file 1: Fig. S9). $\left[{ }^{11} \mathrm{C}\right]$ Pimavanserin did not show any specific binding in pigs.

In our study, blocking experiments in rats without P-gp inhibition detected specific binding for three tracers $\left(\left[{ }^{18} \mathrm{~F}\right] \mathrm{MH} . \mathrm{MZ},\left[{ }^{11} \mathrm{C}\right] \mathrm{Cimbi}-36\right.$ and $\left[{ }^{18} \mathrm{~F}\right]$ Fallypride $)$ and without additional experiments in non-rodent species, the remaining tracers would likely have been discarded. The use of P-gp inhibition helped to additionally identify two tracers $\left(\left[{ }^{18} \mathrm{~F}\right]\right.$ Altanserin and $\left.\left[{ }^{11} \mathrm{C}\right] \mathrm{BA}-10\right)$ that showed specific binding. $\left[{ }^{11} \mathrm{C}\right]$ Pimavanserin did not show any specific binding either with or without P-gp inhibition in rats, and behaved in the same way in pigs. Agreement between pig and rat data on $\left[{ }^{11} \mathrm{C}\right]$ Pimavanserin is a positive finding within the framework of this study, even though it may be perceived as disappointing that a ligand with demonstrated sub-nanomolar affinity and high selectivity towards $5-\mathrm{HT}_{2 \mathrm{~A}}$ receptors [37] turned out to be unsuitable for receptor imaging. Rodent data for $\left[{ }^{11} \mathrm{C}\right] \mathrm{Cimbi}-701$ and $\left[{ }^{11} \mathrm{C}\right] \mathrm{Cimbi}-717$, on the other hand, demonstrate the limitations of brain radioligand evaluation in rodents: even with the use of P-gp inhibition, these tracers would have been discarded based on rodent 
Table 2 Short summary of tracer evaluation in rats, pigs and humans

\begin{tabular}{|c|c|c|c|c|c|}
\hline \multirow[t]{2}{*}{ Tracer } & \multicolumn{3}{|c|}{ Target-specific binding confirmed } & \multirow[t]{2}{*}{ Prediction outcome $^{c}$} & \multirow{2}{*}{$\begin{array}{l}\text { Translated } \\
\text { to humans }\end{array}$} \\
\hline & Traditional $^{\mathbf{a}}$ & P-gpl ${ }^{\mathbf{b}}$ & & & \\
\hline$\left[{ }^{18} \mathrm{~F}\right] \mathrm{MH} . \mathrm{MZ}$ & Yes & Yes & Yes & & Yes \\
\hline$\left[{ }^{18} \mathrm{~F}\right]$ Altanserin & No & Yes & Yes & & Yes \\
\hline$\left[{ }^{11} \mathrm{C}\right]$ Pimavanserin & No & No & No & & \\
\hline$\left[{ }^{11} \mathrm{C}\right] \mathrm{Cimbi}-36$ & Yes & Yes & Yes & & Yes \\
\hline$\left[{ }^{11} \mathrm{C}\right] \mathrm{Cimbi}-717$ & No & No & Yes & & \\
\hline$\left[{ }^{11} \mathrm{C}\right] \mathrm{Cimbi}-701$ & No & No & Yes & & \\
\hline$\left[{ }^{11} \mathrm{C}\right] \mathrm{BA}-10$ & No & Yes & Yes & & \\
\hline$\left[{ }^{18} \mathrm{~F}\right]$ Fallypride & Yes & Yes & Yes & & Yes \\
\hline \multicolumn{6}{|c|}{$\begin{array}{l}\text { Concrete estimates of target-specific binding at baseline an } \\
\text { specific binding in humans are summarized in Additional fil }\end{array}$} \\
\hline \multicolumn{6}{|c|}{ a Traditional evaluation workflow without P-gp inhibition } \\
\hline b $P$-gpl =P-gp inhibit & & & & & \\
\hline
\end{tabular}

data only. Apart from efflux transporter expression and activity, inter-species differences in receptor abundances or metabolic pathways are factors that may have a crucial impact on the translational validation of PET tracers $[38,39]$. Densities of $5-\mathrm{HT}_{2 \mathrm{~A}}, 5-\mathrm{HT}_{7}$ and $\mathrm{D}_{2 / 3}$ receptors in the respective receptor-rich regions of rodent, pig and human brain are summarized from literature data in Additional file 1: Table S4 [28, 40-42]. Densities of 5- $\mathrm{HT}_{7}$ receptors in rat and pig thalamus are very close, so the differences in metabolism between rats and pigs are a more likely explanation for the discrepant results of $\left[{ }^{11} \mathrm{C}\right]$ Cimbi-701 and $\left[{ }^{11} \mathrm{C}\right] \mathrm{Cimbi}-717$ evaluation in these two species.

\section{Conclusions}

The inclusion of P-gp inhibition into the workflow helped to predict the outcome of six out of eight cases (75\% success rate), even though all tracers were strong substrates of P-gp. A traditional evaluation workflow without P-gp inhibition could only predict the outcome for four out of eight tracers (50\% success rate). Our results demonstrate how addition of $\mathrm{P}$-gp inhibition can aid in the interpretation of initial tracer evaluation in rats, improve the translatability and minimize unjustified discontinuations of promising tracers. We believe that the proposed workflow allows for a more effective initial in vivo screening using rats.

\section{Supplementary information}

Supplementary information accompanies this paper at https://doi. org/10.1186/s13550-020-00718-x.

Additional file 1. Detailed overview of the experimental design, description of experiments in pigs, chemical structures of all studied compounds, investigated brain regions on the MRI template, time-activity curves for rat and pig $\left(\left[{ }^{18} \mathrm{~F}\right]\right.$ Fallypride and $\left.\left[{ }^{11} \mathrm{C}\right] \mathrm{BA}-10\right)$ scans, SBR and AUC values for all tracers, numbers of rats scanned per experimental condition are detailed in the Additional file.

\section{Abbreviations}

$5-\mathrm{HT}_{2 \mathrm{~A}}$ : Serotonin receptor of subtype $2 \mathrm{~A} ; 5-\mathrm{HT}_{7}$ : Serotonin receptor of subtype 7; ARRIVE: Animal Research: Reporting of In Vivo Experiments; ATP: Adenosine triphosphate; AUC: Area under the curve; BBB: Blood-brain barrier; BPND: Binding potential relative to non-displaceable uptake; $\mathrm{Cb}$ : Cerebellum; CNS: Central nervous system; $D_{2 / 3}$ : Dopamine receptors of subtypes 2 and 3; FC: Frontal cortex; FELASA: Federation for Laboratory Animal Science Associations; HH: Human head; HRRT: High-Resolution Research Tomograph; MAP-TR: Maximum a posteriori algorithm for transmission data; mPFC: Medial prefrontal cortex; MRI: Magnetic resonance imaging; OP-OSEM3D: Ordinary Poisson 3D ordered subset expectation maximization; PET: Positron emission tomography; P-gp: P-glycoprotein; ROI: Region of interest; SBR: Specific binding ratio; Str: Striatum; TAC: Time-activity curve; Tha: Thalamus; Wb: Whole brain;WT:Wild-type

\section{Acknowledgements}

The authors wish to thank the cyclotron staff at the Department of Clinical Physiology, Nuclear Medicine and PET, University Hospital Copenhagen, 
Rigshospitalet, Denmark, for radionuclide production and technical assistance. We would also like to thank the staff and veterinarians at the Department of Experimental Medicine, University of Copenhagen, for their technical assistance with animal experiments.

\section{Authors' contributions}

$M M H, M P, G M K, S S$ and AK conceived and designed the study; ETL, FGE and VS developed and performed PET tracer synthesis; MX, ETL, VS, IVA, NRR, MP, NRS, SLB, HDH, LLD, AN and STP conducted animal experiments; MX, ETL, NRR, IVA, VS, MP, NRS and $\mathrm{HDH}$ analysed the results; MX, VS, MP, GMK, SS, ETL, MMH and NRR wrote or edited the manuscript. All authors read and approved the final manuscript.

\section{Funding}

This study was supported by funding from the European Union's Horizon 2020 research and innovation programme under the Marie Skłodowska-Curie Grant Agreement No. 813528 as well as from the Savværksejer Jeppe Juhls og Hustru Ovita Juhls foundation. Vladimir Shalgunov was supported by BRIDGE-Translational Excellence Programme (bridge.ku.dk) at the Faculty of Health and Medical Sciences, University of Copenhagen, funded by the Novo Nordisk Foundation. Grant Agreement No. NNF18SA0034956.

\section{Availability of data and materials}

The data sets generated during and/or analysed during the current study are available from the corresponding author on reasonable request.

\section{Ethics approval and consent to participate}

All animal experiments were conducted in accordance with the European Commission's Directive 2010/63/EU, FELASA and ARRIVE guidelines for animal research and with approval from The Danish Council for Animal Ethics (License Numbers: 2017-15-0201-01283 and 2012-15-2934-00156) as well as the Department of Experimental Medicine, University of Copenhagen.

\section{Consent for publication}

Not applicable.

\section{Competing interests}

The authors declare that they have no competing interests.

\section{Author details}

1 Department of Drug Design and Pharmacology, Faculty of Health and Medical Sciences, University of Copenhagen, Jagtvej 160, 2100 Copenhagen, Denmark. ${ }^{2}$ Department of Clinical Physiology, Nuclear Medicine and PET, Copenhagen University Hospital, Rigshospitalet, Blegdamsvej 9, 2100 Copenhagen, Denmark. ${ }^{3}$ Neurobiology Research Unit, Rigshospitalet, Blegdamsvej 9, 2100 Copenhagen, Denmark. ${ }^{4}$ Department of Public Health and Caring Sciences/Geriatrics, Rudbeck Laboratory, Uppsala University, 75185 Uppsala, Sweden. ${ }^{5}$ Radiation Physics, Nuclear Medicine Physics Unit, Skånes University Hospital, Barngatan 3, 22242 Lund, Sweden. ${ }^{6}$ A. A. Martinos Center for Biomedical Imaging, Massachusetts General Hospital, 149 13th Street, Charlestown, MA 02129, USA. ${ }^{7}$ Cluster for Molecular Imaging, Department of Biomedical Sciences, Faculty of Health and Medical Sciences, University of Copenhagen, Blegdamsvej 3, 2200 Copenhagen, Denmark. ${ }^{8}$ Center for Translational Neuromedicine, Faculty of Health and Medical Sciences, University of Copenhagen, Blegdamsvej 3B, 2200 Copenhagen, Denmark. ${ }^{9}$ Institute of Clinical Medicine, University of Copenhagen, Blegdamsvej 3B, 2200 Copenhagen, Denmark.

Received: 27 July 2020 Accepted: 24 September 2020

Published online: 19 October 2020

\section{References}

1. Pysz MA, Gambhir SS, Willmann JK. Molecular imaging: current status and emerging strategies. Clin Radiol. 2010;65:500-16.

2. Matthews PM, Rabiner EA, Passchier J, Gunn RN. Positron emission tomography molecular imaging for drug development. Br J Clin Pharmacol. 2012;73:175-86.
3. Comley J. In vivo preclinical imaging: An essential tool in translational research. Drug Discov World. 2011;11:58-71.

4. Ellenbroek B, Youn J. Rodent models in neuroscience research: is it a rat race? Dis Model Mech. 2016;9:1079-87.

5. Chu X, Bleasby K, Evers R. Species differences in drug transporters and implications for translating preclinical findings to humans. Expert Opin Drug Metab Toxicol. 2013;9:237-52.

6. Uchida Y, Ohtsuki S, Katsukura Y, Ikeda C, Suzuki T, Kamiie J, et al. Quantitative targeted absolute proteomics of human blood-brain barrier transporters and receptors. J Neurochem. 2011;117:333-45.

7. Löscher W, Potschka H. Drug resistance in brain diseases and the role of drug efflux transporters. Nat Rev Neurosci. 2005;6:591-602.

8. Schmitt U, Lee DE, Herth MM, Piel M, Buchholz H-G, Roesch F, et al. P-glycoprotein influence on the brain uptake of a 5-HT2A ligand: $\left[{ }^{18} \mathrm{~F}\right]$ MHMZ. Neuropsychobiology. 2011;63:183-90.

9. Choi JY, Song JS, Lee M, Cho WK, Chung J, Lyoo CH, et al. P-glycoprotein, not BCRP, limits the brain uptake of $\left[{ }^{18} \mathrm{~F}\right]$ Mefway in rodent brain. Mol Imaging Biol. 2016;18:267-73.

10. Syvänen $S$, Lindhe Ö, Palner M, Kornum BR, Rahman O, Långström B, et al. Species differences in blood-brain barrier transport of three positron emission tomography radioligands with emphasis on P-glycoprotein transport. Drug Metab Dispos. 2009;37:635-43.

11. Keller SH, L'Estrade EN, Dall B, Palner M, Herth M. Quantification accuracy of a new HRRT high throughput rat hotel using transmission-based attenuation correction: a phantom study. In: 2016 IEEE nuclear science symposium (NSS) and medical imaging conf room-temperature semicond detect work. IEEE; 2016. p. 1-3.

12. Lemaire C, Cantineau R, Guillaume M, Plenevaux A, Christiaens L. Fluorine-18-altanserin: a radioligand for the study of serotonin receptors with PET: radiolabeling and in vivo biologic behavior in rats. J Nucl Med Soc Nucl Med. 1991;32:2266-72.

13. Mukherjee J, Yang Z-Y, Das MK, Brown T. Fluorinated benzamide neuroleptics-III. Development of (S)-N-[(1-allyl-2-pyrrolidinyl)methyl]-5-(3[18F]fluoropropyl)-2,3-dimethoxybenzamide as an improved dopamine D-2 receptor tracer. Nucl Med Biol. 1995;22:283-96.

14. Herth MM, Debus F, Piel M, Palner M, Knudsen GM, Lüddens $H$, et al. Total synthesis and evaluation of $\left[{ }^{18} \mathrm{~F}\right] \mathrm{MHMZ}$. Bioorg Med Chem Lett. 2008; 18:1515-9.

15. Ettrup A, Hansen M, Santini MA, Paine J, Gillings N, Palner M, et al. Radiosynthesis and in vivo evaluation of a series of substituted 11C-phenethylamines as 5-HT2A agonist PET tracers. Eur J Nucl Med Mol Imaging. 2011;38:681-93.

16. Hansen HD, Herth MM, Ettrup A, Andersen VL, Lehel S, Dyssegaard A, et al. Radiosynthesis and in vivo evaluation of novel radioligands for PET imaging of cerebral 5-HT7 receptors. J Nucl Med. 2014;55:640-6.

17. Hansen HD, Lacivita E, Di Pilato P, Herth MM, Lehel S, Ettrup A, et al. Synthesis, radiolabeling and in vivo evaluation of [11C](R)-1-[4-[2-(4methoxyphenyl)phenyl]piperazin-1-yl]-3-(2-pyrazinyloxy)-2-propanol, a potential PET radioligand for the 5-HT7 receptor. Eur J Med Chem. 2014;79:152-63.

18. Herth M, Hansen H, Anders E, Lehel S, Kristensen J, Billard T, et al. Development of a novel 11C-labelled SB-269970 derivative for imaging the cerebral 5-HT7 receptors. J Nucl Med Soc Nucl Med. 2014;55:1814.

19. Andersen VL, Hansen HD, Herth MM, Dyssegaard A, Knudsen GM, Kristensen JL. 11C-labeling and preliminary evaluation of pimavanserin as a 5-HT2A receptor PET-radioligand. Bioorg Med Chem Lett. 2015;25:1053-6.

20. van Nueten JM, Janssen PAJ, van Beek J, Xhonneux R, Verbeuren TJ, Vanhoutte PM. Vascular effects of Ketanserin (R 41468 ), a novel antagonist of 5-HT2 serotonergic receptors. J Pharmacol Exp Ther. 1981;218:217-30.

21. Lovell PJ, Bromidge SM, Dabbs S, Duckworth DM, Forbes IT, Jennings AJ, et al. A novel, potent, and selective 5-HT 7 antagonist: (R)-3-(2-(2-(4Methylpiperidin-1-yl)ethyl)pyrrolidine-1-sulfonyl)phenol (SB-269970). J Med Chem. 2000;43:342-5.

22. Burt DR, Creese I, Snyder SH. Properties of [3H] haloperidol and [3H] dopamine binding associated with dopamine receptors in calf brain membranes. Mol Pharmacol. 1976;12:800-12.

23. Kallem R, Kulkarni C, Patel D, Thakur M, Sinz M, Singh S, et al. A simplified protocol employing elacridar in rodents: a screening model in drug discovery to assess P-gp mediated efflux at the blood brain barrier. Drug Metab Lett. 2012;6:134-44. 
24. Schiffer WK, Mirrione MM, Biegon A, Alexoff DL, Patel V, Dewey SL. Serial microPET measures of the metabolic reaction to a microdialysis probe implant. J Neurosci Methods. 2006;155:272-84.

25. Scott DO, Heath TG. Investigation of the CNS penetration of a potent 5-HT2a receptor antagonist (MDL 100,907) and an active metabolite (MDL 105,725) using in vivo microdialysis sampling in the rat. J Pharm Biomed Anal. 1998;17:17-25.

26. Tantawy MN, Jones CK, Baldwin RM, Ansari MS, Conn PJ, Kessler RM, et al. [18F]Fallypride dopamine D2 receptor studies using delayed microPET scans and a modified Logan plot. Nucl Med Biol. 2009;36:931-40.

27. L'Estrade ET, Shalgunov V, Edgar FG, Strebl-Bantillo MG, Xiong M, Crestey $\mathrm{F}$, et al. Radiosynthesis and preclinical evaluation of $\left[{ }^{11} \mathrm{C}\right] \mathrm{Cimbi}-701-$ towards the imaging of cerebral 5-HT 7 receptors. J Label Compd Radiopharm. 2020;63:46-55

28. Hansen HD, Ettrup A, Herth MM, Dyssegaard A, Ratner C, Gillings N, et al. Direct comparison of [18F]MH.MZ and [18 F]altanserin for 5-HT 2A receptor imaging with PET. Synapse. 2013;67:328-37.

29. Breedveld P, Beijnen JH, Schellens JHM. Use of P-glycoprotein and BCRP inhibitors to improve oral bioavailability and CNS penetration of anticancer drugs. Trends Pharmacol Sci. 2006;27:17-24.

30. Ramu A, Ramu N. Reversal of multidrug resistance by phenothiazines and structurally related compounds. Cancer Chemother Pharmacol. 1992;30:165-73.

31. Stouch TR, Gudmundsson O. Progress in understanding the structure-activity relationships of P-glycoprotein. Adv Drug Deliv Rev. 2002;54:315-28.

32. Wang $X$, Fang $Y$, Liang J, Yan M, Hu R, Pan X. 5-HT7 receptors are involved in neurogenic dural vasodilatation in an experimental model of migraine. J Mol Neurosci. 2014;54:164-70.

33. Kramer V, Dyssegaard A, Flores J, Soza-Ried C, Rösch F, Knudsen GM, et al. Characterization of the serotonin 2A receptor selective PET tracer (R)-[18F]MH.MZ in the human brain. Eur J Nucl Med Mol Imaging. 2020:47:355-65.

34. Sadzot B, Lemaire C, Maquet P, Salmon E, Plenevaux A, Degueldre C, et al. Serotonin $5 \mathrm{HT} 2$ receptor imaging in the human brain using positron emission tomography and a new radioligand, [18F]altanserin: results in young normal controls. J Cereb Blood Flow Metab. 1995;15:787-97.
35. Ettrup A, da Cunha-Bang S, McMahon B, Lehel S, Dyssegaard A, Skibsted AW, et al. Serotonin $2 \mathrm{~A}$ receptor agonist binding in the human brain with $\left[{ }^{11} \mathrm{C}\right]$ Cimbi-36. J Cereb Blood Flow Metab. 2014;34:1188-96.

36. Mukherjee J, Christian BT, Dunigan KA, Shi B, Narayanan TK, Satter M, et al. Brain imaging of 18 F-fallypride in normal volunteers: blood analysis, distribution, test-retest studies, and preliminary assessment of sensitivity to aging effects on dopamine D-2/D-3 receptors. Synapse. 2002;46:170-88.

37. Vanover KE, Weiner DM, Makhay M, Veinbergs I, Gardell LR, Lameh J, et al. Pharmacological and behavioral profile of $N$-(4-Fluorophenylmethyl)- $N$-(1-methylpiperidin-4-yl) $N^{\prime}-(4-(2-$ methylpropyloxy)phenylmethyl) carbamide (2R,3R)-dihydroxybutanedioate (2:1) (ACP-103), a novel 5-hydroxytryptamine 2A receptor inverse agonist. J Pharmacol Exp Ther. 2006;317:910-8.

38. Fowler JS, Ding YS, Logan J, Macgregor RR, Shea C, Garza V, et al. Species differences in [11C]clorgyline binding in brain. Nucl Med Biol. 2001;28:779-85.

39. Ma Y, Lang L, Kiesewetter D, Jagoda E, Eckelman WC. Species differences in metabolites of PET ligands: serotonergic 5-HT1A receptor antagonists 3-trans-FCWAY and 3-cis-FCWAY. Nucl Med Biol. 2006;33:1013-9.

40. Herth MM, Knudsen GM. PET imaging of the 5-HT2A receptor system: a tool to study the receptor's in vivo brain function. In: Guiard B, Di Giovanni $G$, editors. 5-HT2A receptors in the central nervous system. Cham: Humana Press; 2018. p. 86-135.

41. L'Estrade ET, Erlandsson M, Edgar FG, Ohlsson T, Knudsen GM, Herth MM. Towards selective CNS PET imaging of the 5-HT7 receptor system: past, present and future. Neuropharmacology. 2020;172:107830.

42. Cumming P. Absolute abundances and affinity states of dopamine receptors in mammalian brain: a review. Synapse. 2011;65:892-909.

\section{Publisher's Note}

Springer Nature remains neutral with regard to jurisdictional claims in published maps and institutional affiliations.

\section{Submit your manuscript to a SpringerOpen ${ }^{\circ}$ journal and benefit from:}

- Convenient online submission

- Rigorous peer review

- Open access: articles freely available online

- High visibility within the field

- Retaining the copyright to your article

Submit your next manuscript at $\boldsymbol{\nabla}$ springeropen.com 